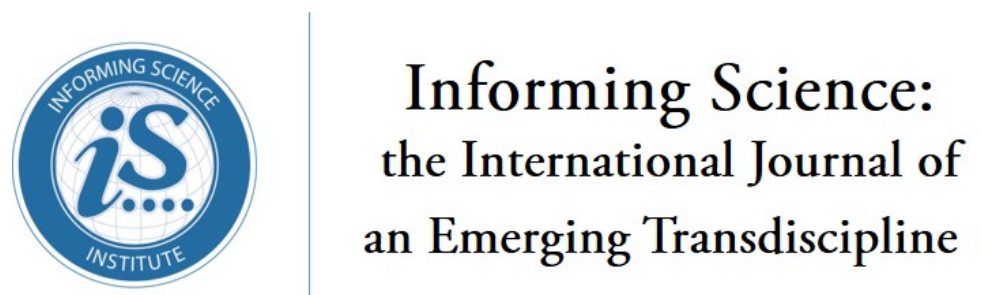

An Official Publication

of the Informing Science Institute

InformingScience.org

Inform.nu

Volume 21, 2018

\title{
DIGITAL MEANS FOR REDUCING DIGITAL INEQUALITY: LITERATURE REVIEW
}

Elena Maceviciute*

Tom Wilson
Digital Media Laboratory, Faculty of Communication, Vilnius University, Vilnius, Lithuania elena.maceviciute@gmail.com

wilsontd@gmail.com

\begin{abstract}
Digital Media Laboratory, Faculty of Communication, Vilnius University, Vilnius, Lithuania
\end{abstract}

\section{ABSTRACT}

Aim/Purpose The aim of this paper is to identify the possibilities for reducing the second and third levels of the digital divide (or inequality) through conscious application of digital technologies, especially through the promotion of digital means for information, enlightenment, and entertainment.

Background This article reviews studies carried out between 2000 and 2017, which investigate the social benefits of digital technology use for disadvantaged user groups and, especially, of their outcomes in terms of increasing digital skills and motivation to use information and communication technologies.

Methodology The literature review of the selected texts was carried out using thematic content analysis. The coding scheme was open but based on the theory of three levels of digital divide by van Dijk.

Contribution

The results of the analysis show the difficulties related to the attempts of reducing the digital divide on the second and third level using only digital interventions, but also reveal the potential of these interventions.

Findings

The literature review confirms the connection of different levels of digital divide with other relational and structural inequalities. It provides insights into the strengths and weaknesses of digital interventions aimed at the reduction of digital inequalities. Their success depends on the consideration of the context and participants needs as well as on carefully planned strategies.

Accepting Editor Eli Cohen | Received: August 4, 2018 | Revised: September 4, September 7, 2018 | Accepted: September 8, 2018.

Cite as: Maceviciute, E., \& Wilson, T. D. (2018). Digital means for reducing digital inequality: Literature review. Informing Science: the International Journal of an Emerging Transdiscipline, 21, 269-287. https://doi.org/10.28945/4117

(CC BY-NC 4.0) This article is licensed to you under a Creative Commons Attribution-NonCommercial 4.0 International License. When you copy and redistribute this paper in full or in part, you need to provide proper attribution to it to ensure that others can later locate this work (and to ensure that others do not accuse you of plagiarism). You may (and we encourage you to) adapt, remix, transform, and build upon the material for any non-commercial purposes. This license does not permit you to use this material for commercial purposes. 
Recommendations for Practitioners

Recommendations for Researchers Impact on Society

Future Research

Keywords
While planning a digital intervention with the aim of reducing digital inequalities, it is necessary to assess carefully the context and the needs of participants. Educational interventions should be based on suitable didactic and learning strategies.

More research is needed into the factors that increase the effectiveness of digital interventions aimed at reducing the digital divide.

The paper summarizes and demonstrates the shortcomings and limitations of poorly designed interventions in reducing the digital divide but emphasizes the possibilities of raising the motivation and benefits for the participants of strategically planned and implemented projects.

We will apply the findings of this literature review in an intervention in the context of Lithuanian towns of different sizes.

digital divide, digital technology, literature review, reducing digital inequalities

\section{INTRODUCTION AND BACKGROUND}

The aim of this paper is to identify the possibilities for reducing the second and third levels of the digital divide or digital inequality (see explanation in Figure 1) through conscious application of digital technologies, especially through the promotion of digital means for information, enlightenment, and entertainment. Our interest is guided by our involvement in a project that requires the design of an intervention to increase digital inclusion of certain disadvantaged groups in Lithuania.

We looked for studies carried out between 2000 and 2017, which investigate the social benefits of digital technology use for disadvantaged user groups and, especially, of their outcomes in terms of increasing digital skills and motivation to use information and communication technologies.

The concepts of digital divide and the reduction of digital inequality are multi-dimensional and involve examination of several complex issues, such as inequality, digital divide, social exclusion and inclusion, approaches and measurement of social exclusion, general means of reduction of inequality, role of digital technologies in society, and more. Therefore, we inevitably need to limit the text to the exploration of the different digital means used for the reduction of the digital divide, focusing on its second and third levels.

The research questions we seek to answer as a result of the review are:

1. Which groups and areas are addressed in research investigating measures of increasing digital inclusion by the means of digital technologies?

2. What are the aims, methods, and results of the research into digital means of reduction of the second and third levels of the digital divide?

Digital inequalities manifest themselves internationally among countries with different economic development and, within countries, among different social groups. Inside any country, the national economy will define the general living standards; however, different social groups and even different individuals belonging to the same group will possess different economic, social, educational, and cultural capital. We are interested in the latter phenomena within the societies inside countries. Therefore, it is useful to understand the roots of the digital divide and its relation to social inequality.

Inequality in societies is not restricted to the digital domain and, to understand its impact, it is necessary to consider the nature of inequality more generally. Inequality has risen high on the agenda of economists since the 2008 financial crash and the implementation by many Western countries of austerity programmes, which seem to have worked to increase income inequality, rather than to ame- 
liorate it. This has led to warnings, by the World Bank, for example, that, "the gap between rich and poor risks thwarting its ambition of eliminating extreme poverty by 2030" (Elliott, 2016). The OECD (2016) has warned that "income inequality levels have remained at historical highs." Other organizations, such as Oxfam (2017) and the United Nations Development Programme (2009), have also emphasized income inequality in their analyses. The means to deal with inequality in society are mainly political. Many researchers point out that the taxation system is clearly one of the main means whereby a society can reduce income inequality (e.g., Bjorklund \& Freeman, 1994; Koike, 2015). It would be in accord with Rawls's second principle of justice, "While the distribution of wealth and income need not be equal, it must be to everyone's advantage" (Rawls, 1999, p. 53).

Income inequality denies the possibility of 'fair equality of opportunity' because of its association with virtually all other inequalities, such as access to health care, access to education, and so on. It is also closely associated with digital inequality, especially, the first level, which requires political decisions on the infrastructural level. Van Dijk (2012) suggests that digital inequality is increasingly important in a network society and may lead to structural inequalities, excluding a majority of the population from active participation in that network society, not to speak of the most vulnerable groups (p. 73). However, the situation can be alleviated by a variety of political, economic, educational, and other measures. Any of these measures will have to address or employ digital technologies to decrease the digital divide and combat social exclusion. The first level, that of inequalities in physical access, is a domain of state policy and the results of the relevant political measures are usually assessed using representative population surveys. Our purpose was to explore the research carried out with the aim of decreasing social inequalities by employing digital means in diverse educational, cultural, or social contexts, regardless of their scale, and to identify the sectoral and organizational possibilities to diminish the digital divide. We expect to identify successful approaches to digital inclusion and diminishment of the digital divide through exploring smaller studies and experiments using qualitative or mixed methods.

The following text includes:

- The explanation of our theoretical approach.

- The methods used in conducting this literature review.

- Two parts presenting the results of literature analysis:

0 the first on research connecting digital divide manifestation to relational inequalities,

$\circ$ the second on studies of interventions to reduce digital inequalities.

- Discussion of the results and conclusion.

\section{THEORETICAL APPROACH}

The issues of digital divide are often treated as the disparities in adoption, diffusion, and utilization of information and communication technologies. This approach is demonstrated in the article by Pick and Sarkar (2016) comparing adoption-diffusion, the unified theory of acceptance and use of technology theories, spatially aware technology utilization, and digital divide models. However, we see the digital divide as an issue of social inequalities, social inclusion, and exclusion and searched for the theoretical model with this concept in mind.

The limitations of the notion of a digital divide have been addressed by Warschauer (2002), who notes that the idea of a binary divide into the 'haves' and 'have nots' can be patronising, typifying certain social groups as 'have nots', when, in fact, the employment of the technology by members of those groups (e.g., Black Americans in the US), varies according to their income level. Warschauer states:

"The bottom line is that there is no binary divide, and no single overriding factor for determining such a divide. ICT does not exist as an external variable to be injected from the outside to bring about certain results. Rather, it is woven in a complex manner in social systems and processes. And, from a policy standpoint, the goal of using ICT with marginalized groups is not to overcome a digital 
divide, but rather to further a process of social inclusion" (Warschauer, 2002, para. 27), i.e. improving the opportunities and opening possibilities for individuals and groups to take part in the life of society and community.

Sassi (2005) has identified four conceptual approaches to the digital divide. The technocratic approach sees the diffusion of digital technologies as a way to create an information society and regards the differences in their use as occasional and temporary. The other three approaches are overlapping and build on each other. The social structure approach sees digital inequalities as structural and dependent on basic social differences and only disappearing with the removal of social differences. The exclusion approach regards information technology as not only strengthening basic structural inequalities, but also creating new ones. The modernization approach sees digital technology and the social economic system as interdependent structures where digital networks are used as new ways of controlling industrial and social systems and can be changed in the process (p. 692, 695). Van Dijk's digital divide concept belongs to this latter approach and we have chosen this concept which also allows us to bring together individual, institutional, and societal interactions with different levels of digital inequalities. One should point out that these levels may also be found in other approaches as the elements of manifestations of the digital divide.

Recognition of the problems with the divide concept has led to the realisation that digital inequality is not simply a single, binary concept. The concept of relational inequality (categorical differences between groups of people) (Tilly, 1998) has been used to explain the present digital divide by van Dijk (2005). The author shows how dominant groups appropriate resources and societal norms and how this affects the unequal diffusion and adoption of new technologies, which in turn increases categorical inequalities. He also emphasizes different positions along the continuous spectrum of inequalities: from absolute exclusion of access to digital media to differences in economic and social benefits obtained through skilful and informed usage of digital technology (van Dijk, 2012). The appropriation of the technology depends on different kinds of access and the basis of it rests on motivation to use the technology (see Figure 1). Van Dijk sees motivation as one of the levels of the digital divide. However, it is often explored as a general factor of acceptance of innovations and technology (Venkatesh, 2000). In our interpretation, motivation increases with technology diffusion in society and can be explained both by social or cultural (income and education) and mental or psychological (psychological type or phobias) factors, but also as an outcome of increased digital skills and usage. Thus, we explore motivation as a possible effect (a result) of measures decreasing or increasing digital inequality.

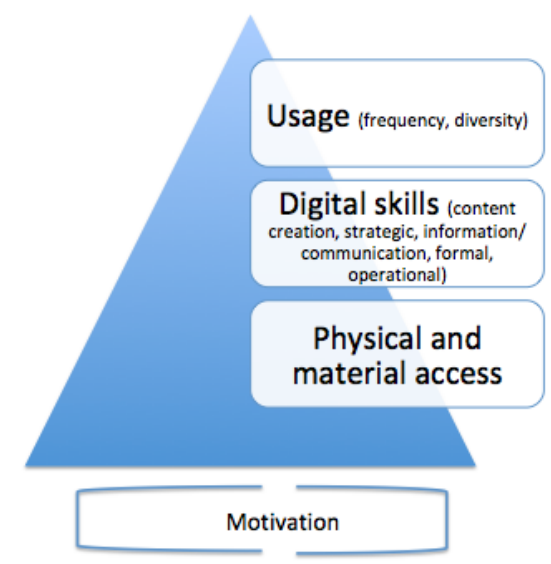

Figure 1: The levels of digital divide (based on van Dijk, 2012)

The first level of the digital divide includes physical and material access. It includes the diffusion of Internet connection and penetration of computers or other digital devices into workplaces and 
households. It is related to reducing prices for basic connections and equipment types, and it is predicted that eventually "the lower social strata... are starting to catch up and the divide narrows" (van Dijk, 2012, p. 65), though does not disappear altogether.

The second level of digital divide consists of inequalities in a wide range of "digital skills" (p. 67). Van Deursen and van Dijk (2010) have developed six types of Internet skills and the inequalities that can manifest within each of these types.

The highest, third level of the divide, relates to technology appropriation and use that can be measured in time and frequency, diversity and quality of used applications, and the benefits derived from the usage of technology.

Van Deursen et al. (2017) investigated the relations between different levels of the digital divide. Evidence was found of compound and sequential forms of digital inequality among Dutch Internet users. Compound inequality means that the lack of offline capital in one area (e.g., economic) will reduce the benefits derived from Internet use in this area, but not necessarily in another (e.g., cultural). Sequential inequality manifests itself when, for example, the lack of technical or information seeking skills affects different types of Internet use in many areas and diminishes derived benefits. These findings demonstrate that the digital divide is even more varied than was earlier anticipated.

For our purposes and from our standpoint of library and information science, we are mainly interested in the second (digital skills) and third (use benefits) levels of digital divide as our interventions can mainly affect the individual know-how and motivation to use digital technologies, but we are also interested in finding out how experiments directed towards diminishing digital exclusion affect the offline life of the subjects and if the researchers have paid attention to the influence of the social background of the subjects on the results of digital interventions.

\section{METHOD}

We chose Scopus and Google Scholar as our databases for searching the literature, as these sources offer a greater variety of material than does the Web of Science.

On Scopus, the search strategy, ("digital divide" OR "digital inequal*") AND ("social inclusion" OR "social exclusion") produced 164 papers published since 2000. The most active years were between 2007 and 2017, with 76 per cent of the total papers being published in these years. This is reflected in the texts selected for our review with only a small number of articles from the years 2000-2007.

Analysis of the papers by the subject field to which the source is assigned by Scopus shows that the subject is predominantly of interest to the social sciences and computer science. There is some double assignment of fields to journals and, consequently, the total number of assignments exceeds the total number of papers. Thirty-four per cent of the assignments are to the social sciences and 28.6 percent are to computer science. There are, occasionally, papers in a wide range of other fields, including psychology, mathematics, medicine, and environmental sciences, illustrating the wide range of disciplines with interests in digital inequalities. The same search on Google Scholar produced more varied results and included project reports and official documents added to the review.

The criteria used for the selection of the texts were as follows: we have favoured empirical research over mere descriptions; selected the studies relating digital inequalities to social inequalities; selected studies of explicit interventions with the aim of reducing digital inequalities, rather than as an afterthought; prioritized cases of interventions on the community level; selected studies with empirical evidence of intervention effects on participants.

As we expected, in most of the literature, the second and third level of digital divide are addressed as well as the motivation to use the technology. In some cases, studies explored the results of providing access to digital equipment, but in general physical access to the digital technologies has to be provided in the first place to conduct further interventions. 
The articles that we have selected for this review were analysed using thematic content analysis. We used an open list of themes based on the theoretical model, which was augmented with emerging additional themes. Both researchers did independent coding and then compared the results. In cases when a discrepancy between the codes was found, the researchers discussed the issue and assigned a commonly agreed upon code. The whole body of literature was analysed, but only the most typical examples are cited in this text.

The texts fall into two main parts. The first covers the issues of the relation of the digital divide (or inequality) to other structural or relational inequalities. They provide empirical data proving the reciprocal relation of these inequalities (e.g., van Dijk, 2012).

As for the second part, there is significantly less published research dealing with interventions aiming to reduce the digital divide in particular social groups or geographical areas, however, collecting what is available shows much wider distribution of the publications along different fields of research.

\section{RESEARCH ON THE MANIFESTATION OF DIGITAL INEQUALITY}

\section{PHYSICAL AND ECONOMIC ACCESS TO DIGITAL TECHNOLOGIES}

The Internet World Stats site draws its data from a variety of reliable sources and shows that in March 2017 almost half of the world's population (49.7\%, or 3,739,698,500 people) now has access to the Internet. There are, of course, inequalities, such that in Africa only $28.3 \%$ of the population has access, whereas in North America, the proportion is 88.1\% (Internet World Stats, 2017a). In Europe, inequalities also exist, with $43.4 \%$ penetration in the Ukraine, compared with $100 \%$ in Iceland. Analysis of the Internet World Stats data shows that more than half (38) of the countries in Europe (including those outside the European Union) have penetration levels of $80 \%$ or more, while only 15 have below 70\% penetration (Internet World Stats, 2017b). As for connection speeds, according to the Akamai state of the Internet report for the first quarter of 2017 (Akamai, 2017, p. 3), South Korea has the highest average connection speed at 28.6 mbps; Norway and Sweden follow closely behind with speeds of $23.5 \mathrm{mbps}$ and $22.5 \mathrm{mbps}$, respectively. Lithuania, with an average of 14.6 mbps ranks 28th in the world and is about in the middle of the European rankings.

The overall access figures for countries mask the inequality that exists within countries. For example, a report from the Oxford Internet Institute identifies the north-east of England as the most disadvantaged area in the UK, with less than $70 \%$ of people accessing the Internet, compared with London, with 85\%, and even the rural area of Cornwall, with usage rates in the $80 \%$ range (Blank, 2014). In relation to connection speeds, Ofcom (the agency responsible for regulation of the telecommunications industry in the UK) reported that, in late 2016, the average broadband speed experienced by consumers was $36.2 \mathrm{mbps}$, largely as a result of the take-up of so-called 'superfast' broadband connections. However, the average speed in rural areas was less than $10 \mathrm{mbps}$, compared with $40 \mathrm{mbps}$ in urban areas (Ofcom, 2017). In Lithuania, the same urban/rural divide exists, with users in the main cities being able to access services with speeds up to $100 \mathrm{mbps}$, but less than $10 \%$ of those in the country districts being able to do so (RaskInterneta, 2017). In the USA, average connection speed is now, reportedly (Ookla, 2016) more than $50 \mathrm{mbps}$, but the speed attained depends on the provider, mode of provision, and price. The Federal Communications Commission reported in 2016 that the median speed of connection was $36 \mathrm{mbps}$, with the best speeds being delivered by optical fibre providers, led by Verizon, with the lowest performance by suppliers of DSL and satellite connection (Federal Communications Commission, 2016).

From these data, and their collection over time, it is clear that the first divide, that is, the physical access to universal, high-speed Internet connection, is gradually closing in most of the developed world and that access to the network will become a matter of being able to pay for that connection. Thus, income inequality will affect digital inequality. 


\section{GROUPS AFFECTED BY DIGITAL INEQUALITY}

Research in many countries before and after the millennium (U.S. National Telecommunications and Information Administration, 1995; 1998; 1999) finds that similar groups are affected by digital inequality, because of the connection to income inequality. Low-income households, single-parent families, the elderly, and those living in rural areas, are mentioned as most affected. The most recent report from the NTIA (Carlson \& Goss, 2016) shows that the gap between rural and urban areas in Internet use has remained at "a fairly constant 6-9 percentage point gap", although use in both areas has climbed from about 30\% in 1998 to about $80 \%$ in 2015 . Similarly, the gap between high income families and low-income families has remained: nationally, $86 \%$ of households with incomes above $\$ 100,000$ a year report Internet use, compared with $57 \%$ of households with incomes below $\$ 25,000$ a year (Carlson \& Goss, 2016).

A recent paper by Fairlie (2017) concludes that "the "digital divide" based on ethnicity and race has not been bridged in the US and remains as large as it was two decades ago." A cross-national study by Chen and Wellman (2004) showed that, in the UK, Germany, and South Korea, inequality in Internet access in relation to 'socio-economic status', i.e., household income, was actually increasing, while in the US and Japan, it was 'declining yet persistent'. In China and Mexico, it was typified as 'buge' and in Italy, there was a significant gap related to level of education.

The male/female gap was non-existent in the US, 'declining yet persistent' in the UK, Japan, and China, and increasing in Germany and Italy. Two studies have shown the difference in women's use of social technologies in different countries and relevance of these technologies to closing a more general gender gap (Nord, Paliszkiewicz, Grublješič, Scarlat, \& Svanadze, 2015; Nord, Lee, Cetin, Atay, \& Paliszkewicz, 2016). In relation to 'life stage' (or the gap between the young and the elderly), in most of the eight countries covered in the study, inequality was declining. Countries also experience an urban/rural divide in access (Carlson \& Goss, 2016) even in advanced societies (Salemnik, Strijker, \& Bosworth, 2017). In Lithuania, reviews of digital development over several years have identified a persistent gap of access to and use of IT in big cities and rural regions (Žilinskas, 2011; 2012).

Ono and Zavodny (2008) have established an increasing digital inequality between Spanish-speaking immigrant and English-speaking households in the US since 2003. A study in Norway found that in addition to other factors, children with immigrant backgrounds (speaking at home Norwegian and another language or only another language) are less digitally competent (Hatlevik, Björk Guðmundsdóttir, \& Loi, 2015).

The national picture regarding computer and Internet use will affect the situation: thus, a study in

Hong Kong (Kwong, 2015) reported that the Internet was used by only $18 \%$ of persons aged 65 years and over, while the US Census recorded $51 \%$ of the same age group using the Internet from home or from some other location (US Census Bureau, 2014). Liubiniene and Thunqvist (2015) found that, in Lithuania, the main factor affecting the level of digital media literacy and, as a result, digital inequality, is age. In Sweden, the generation gap is much less evident.

Thus, general explorations provide evidence not only of the persistence of a digital divide, but also of more complicated issues of relational inequalities.

\section{WITHIN GROUP INEQUALITIES}

Relational inequalities emerge also within the same group. An Italian study of 900 persons between the ages of 65 and 74 (Colombo, Aroldi, \& Carlo, 2015) found that those respondents who were using the technology were better off financially, had stable work situations, and were more highly educated. Access to the Internet was incorporated into their daily life: once these people cross the threshold of access, individuals become mature users in all senses and cease to be occasional visitors (Colombo et al., 2015, p. 54 [Our translation]). However, the authors have stated a growing polarization between the rich and the poor within this group, where a large proportion of older people remain disconnected and at risk of marginalisation (due to broader social factors), while for a minority 
of users (economically and socially), digital media have penetrated daily life with great force, in terms of time spent and economic and relational investment (Colombo et al., 2015, p. 55 [Our translation]).

They go on to acknowledge that this may be a generational phenomenon, and that future generations, that have used computers and the Internet throughout their working lives, may well continue to do so in their later years.

An Australian study of refugees also found a digital divide among refugees "based on inequalities in physical access to and use of digital technology, the skills necessary to use the different technologies effectively and the ability to pay for the services" (Alam \& Imran, 2015, p. 344). The cross-cultural study of Sweden and Lithuania has provided evidence of a digital divide and low media literacy of socio-economically marginalized groups, mostly immigrants or unemployed people (Liubinienè \& Thungqvist, 2015, p. 146).

\section{BARRIERS, MITIGATORS AND BENEFITS IN THE USE OF DIGITAL TECH- NOLOGIES}

Some research is specifically concerned with the second level of digital inequality, that is, the ability to use the technology effectively, see for example the study by Hargittai (2002), that established a connection between socioeconomic background and Internet skills.

Thus, a study conducted in the US (Tsai, Shillair, Cotton, Winstead, \& Yost, 2015) identified technological self-efficacy as a factor inhibiting the use of computers by older people. The researchers conducted interviews with elderly persons who already had a tablet computer. In $38 \%$ of the cases, the person had received the tablet as a gift, just under one half $(47 \%)$ had seen other people using them and decided to buy for themselves, and 19\% had an opportunity to use someone else's device and had then bought their own. A crucial factor in gaining facility in using the device was its ease of use, which applied to both iPads and Kindle readers; gaining competence rapidly overcame any fears they might have had initially.

However, the authors note that many of their respondents had previous experience with computers, so learning how to use an iPad would not be particularly difficult. In this respect the interviewees were not, perhaps, typical of the older members of society. This latter point appears to be borne out by a Canadian study (Quan-Haase, Martin, \& Shreurs, 2016), which studied "digital seniors", i.e., persons between the ages of 60 and 84, who were users of the technology. In a high proportion of cases, these were people whose professions would have required computer use and the main findings related to their adopting new uses for the technology. Both studies pointed out that there were a number of advantages these older people gained from the use of tablet computers: keeping in touch with friends and family, keeping up-to-date with current affairs, and pursuing their special interests.

An earlier research review from the UK (Green \& Rossall, 2013) looked into the barriers that affect computer and Internet use by senior citizens in the UK and showed that "there is a decreasing likelihood of using the Internet as age increases", especially, for those with the lowest income and lower perceived health status (p. 7). Despite the same benefits from Internet use as noted above, there are many barriers to the use of digital technology: perceived lack of need, lack of awareness, previous experience or skills, fear of computers, concerns about security, and lack of trust (p. 16-19).

Wilding (2012) demonstrated that accessible information and communication, especially mobile technologies, are important for young refugees to offset the threat of marginalization and to seek positive social and cultural identities and experiences. Lloyd, Kennan, Thompson, and Qayyum (2013) found a relation between information literacy of refugees, digital divide, and social inclusion, i.e., their ability to overcome barriers preventing full participation in new communities. Further, Lloyd, Pilerot, and Hultgren (2017) have suggested that: 
"Technology is instrumental in building both bonding and bridging capital, allowing refugees to maintain familial and trans-global alignments and to build social networks that support economic aspirations" (p.11).

A study of refugees in Australia used focus groups as the data collection method and participants clearly understood the value of Internet connectivity as an aid to their daily lives, enabling them to search for jobs, to communicate with each other and with relatives abroad, and for accessing goods and services. The main barriers to gaining access were the lack of financial resources, together with an initial lack of language skills, and familiarity with the technology. Those without home connections used the public library, which, for some, had the disadvantage of being some distance from their homes, and the library of the educational institution where they were learning language and other skills (Alam \& Imran, 2015).

\section{THE THIRD LEVEL OF THE DIGITAL DIVIDE}

Researchers have also addressed the third level of the divide (i.e, inequalities in the diversity of Internet use and in the benefits derived from use), although it is a rarity so far. Van Duersen and Helsper (2015) have reviewed earlier work about the outcomes of Internet use and identified eight categories of benefits that can be derived from such use: economic use related to commerce, economic use related to labour, social uses, educational uses, political uses, use of government institutions, and use of health institutions (p. 38). Their survey of a representative sample of the Dutch population has shown that "access to and use of the Internet might amplify existing inequalities above and beyond the intensity of Internet use" (van Duersen \& Helsper, 2015, p. 45). Other data support this suggestion, for example, showing that highly educated individuals get more economic commerce, institutional government, and educational benefits from the Internet than those less educated. Also "economic resources such as income and occupation are strongly related to economic outcomes and political and institutional outcomes" (p. 46).

Thus, it is important to monitor how Internet use contributes to the offline outcomes and deepens the third level digital divide. A recent analysis of representative survey data of adults in the US shows that web-use skills and diversity of Internet activities differ among older adults: those with higher socioeconomic status are more likely to benefit from the diversity of Internet use (Hargittai \& Dobransky, 2017). A study based on Pew survey data shows that smartphones help to bridge the divide in physical access, but do not close the usage gap. Differences in smartphone dependence and use are based on race, age, income, and education. Though less advantaged group members are more likely to be smartphone-dependent, they use smartphones for more social activity, while individuals from more advantaged groups exploit them more for news and information (Tsetsi \& Rains, 2017).

Another study of immigrants to New Zealand found that a positive attitude towards the technology was a major influence on its adoption and strong motivation coming from family, friends, and the wider ethnic community could overcome the economic (low income) barriers in acquiring computers and access to the Internet at home (Kabbar \& Crump, 2006, p. 117). However, skills and usage benefits were important obstacles, so the self-confidence of many participants was low, or the computers were used in a limited way as communication tools. The awareness of such possibilities as English language learning sites, Internet banking, job seeking, or accessing local and central governmental services for health or educational purposes was very low or non-existent. The lack of relevant online content in accessible languages also became a significant barrier in adopting the technologies (p. 116, 117).

Thus, research supports the connection between social inequalities and the digital divide on different levels. We also looked into the research providing evidence that actually some manifestations of digital and social inequality can be addressed by increasing digital and information skills and increasing the benefits derived from Internet use by disadvantaged group members. 


\section{RESEARCH ON “DIGITAL INTERVENTIONS" FOR THE REDUCTION OF DIGITAL INEQUALITIES}

The research on what we deemed "digital interventions" with the aim of reducing digital inequalities is not abundant, but it is building up especially in some areas, such as education and child literacy.

\section{CHILD LITERACY AND EDUCATION}

A series of educational experiments had the aim to assess computers as pedagogical mechanisms providing "equal opportunity and the required context to children from all types of socioeconomic and cultural backgrounds, to learn and achieve basic levels of literacy and education" (Mitra et al., 2005 , p. 408). Over multiple experiments, using public access to computers and digital online or offline resources all over the world, Mitra and his collaborators have shown that disadvantaged children can learn by themselves or with minimal support from adults, and can not only acquire significant levels of computer literacy (Mitra et al., 2005), but also study quite complex materials in a little known language and achieve results comparable with those of the affluent students from well-staffed schools (Mitra \& Dangwal, 2010). These researchers continue testing what they call the "selforganized learning environments" and "self-organized mediation environments" in disadvantaged rural areas of India and urban areas in Northeast England. Digital technologies play a central role in acquiring knowledge and getting adult support in these experiments.

Another interesting experiment was aimed at large-scale improvement in literacy and reading skills by using digital technologies in so-far illiterate communities that lacked pre-schools. The first stage, involving planting tablet computers with pre-selected apps and texts in two remote and isolated villages in Ethiopia, was successful (Wolf, Ullman-Shade, \& Gottwald, 2012): in a year, forty children, who had never seen any written text in any form found out how to use the tablets, learned the alphabet and acquired other skills required for reading, and selected the most helpful applications. This success opens the possibilities for further application of digital technology to introduce literacy and develop reading habits around the world and to disadvantaged groups in developed countries (Wolf, Gottwald, Breazeal, Galyean, \& Morris, 2017).

Several research groups have taken advantage of state-supported programmes for students at schools in several Latin American countries to carry out investigation of the impact of computer technology diffusion on mitigation of digital inequalities (e.g. Plan Ceibal in Uruguay, Programa Enlaces in Chile, Programa Conectar Igualdad in Argentina). We have looked closely at the semi-structured interview study of the programme in Argentina (Larghi, Lemus, Moguillansky, \& Welschinger, 2015), in which Programa Conectar Igualdad (PCI), focused on young people, delivering more than 3.5 million netbooks to schools throughout Argentina and distributing them to students. The researchers interviewed students from two schools that benefited from the programme. The first school was attended by pupils from affluent middle-class families, while the second consisted of children from low income, working class families. Larghi, et al. (2015) studied the impact of the programme in the two schools, collecting data through interviews with 20 students in each school, finding that the PCI had provided the first computers to the lower-class youths and a diminished digital skills gap between the two groups:

"there is evidence of more diverse and increased use of ICTs among lower class students, revealing the development of digital skills related to educational activities. Since these skills were already largely present in middle class families, the PCI tends to reduce the first and second levels of the digital divide." (p. 2-3)

The availability of their own computers reduced the reliance of working-class youth on cybercafés and other public access points and "provided them with new opportunities" (Larghi et al., 2015, p. 13-14) to search for meaningful information, do homework, access digital resources, and communicate with family and friends. In addition, it introduced digital technologies into their family and many 
parents started using the computers themselves or procured an Internet connection at home. The students from both groups emphasized the importance of teachers and their digital skills for using the netbooks for different subjects. On the other hand, the difference in the previous accessibility to and experience of digital technologies resulted in persisting inequalities of the types and variety of computer and Internet use, e.g. "in less intensive use of spreadsheets, text editing and graphic presentation software" (p. 13-14).

The study is interesting in that it demonstrates, very clearly, how a well-directed, public policy can help to mitigate the digital inequalities that arise out of endemic social inequalities. The grouping of the dimensions of digital inequality in the study is also of interest, identifying access and connectivity (the first divide), technological skills (the second divide), computer and Internet use (the third divide), and what we may need to call a fourth divide, 'forms of appropriation of online virtual social networks.'

The use of computer technology may not always have beneficial effect in education, however. A study in the US following the impact of introduction of home computers and broadband on learning achievements, found, somewhat counter-intuitively, that, "the introduction of home computer technology is associated with modest, but statistically significant and persistent negative impacts on student math and reading test scores" (Vigdor, Ladd, \& Martinez, 2014, p. 1103) and increasing digital inequalities. The study found that:

"The evidence is consistent with the view that Internet service, and technology more broadly, is put to more productive use in households with more effective parental monitoring of child behavior" (p. 1117)

suggesting that 'bridging the divide' is only part of the problem of educational inequality and that teaching effective use of the technology must also be considered.

The latter two studies take us to the issues of social and community background in the introduction of digital technologies as the means of addressing digital inequalities.

\section{DISADVANTAGED COMMUNITIES}

Loader and Keeble (2004) conducted an overview of community informatics initiatives from the late 1990 s to the beginning of the 2000s, focusing on some innovative projects for creating community learning environments, regeneration of deprived communities through provision of ICTs, increasing civic participation through e-democracy means, and citizenship education. The overall conclusions show a lack of evidence that community informatics initiatives are closing the digital divide. They are more beneficial to those who are already better educated and more familiar with ICTs and rarely attract those who would benefit most (Loader \& Keeble, 2004, p. 41-42).

Another major study by the Information Society Unit at the EU Joint Research Centre (Stewart et al., 2013) explored the potential of digital games for social inclusion of groups at risk. The researchers investigated a number of case studies in Europe and the US, in which digital games were employed in different settings to increase the awareness of social inclusion forms, to alleviate the community problems or individual suffering of people with health problems. Most of the games were used in educational settings. Although the results were not entirely reliable or sufficient in all cases, the investigation has shown that digital games can be intrinsically motivating to the players by "bringing sense of confidence, belonging and autonomy", "improve social skills and foster communities", provide safe space for participation and learning, and support the development of core and transferable skills (Stewart et al., 2013, p. 67-70).

In yet another study, Kvasny and Keil (2006) report on interventions carried out in two cities in Georgia (US), LaGrange and Atlanta. In LaGrange, free access to the Internet was provided to citizens in a deprived area of the city, while, in Atlanta, "Cyber Centers" were set up in the poorer parts of the city. In the centres, citizens could receive free training and free access to computers. The re- 
sults of the evaluation showed that in LaGrange, only $45 \%$ of eligible households had adopted the technology and the city manager commented:

"We really thought the folks without computers were going to jump all over it. And what we learned is that the digital divide is not necessarily an economic problem exclusively, because economics are [sic] not a part of this deal. The problem exists on a host of levels, money is one of them, desire, interest, willingness to learn is another part of it" (Kvasny \& Keil, 2006, p. 45).

In Atlanta, on the other hand, the programme appears to have been very successful: the thirteen centres trained more than 15,000 citizens in their first eighteen months of operation. It is clear, however, that it was not viewed as a success by all of the participants, who were disappointed that it did not lead to them getting a job, in other words, deriving benefit from the training was problematic. Thus, even when training appears to be well-organized and well-targeted, as in the Atlanta case, some of the participants have hopes of benefits that training alone cannot provide. Computer skills, including Internet skills, may be desirable for all kinds of jobs and to support daily living, but participants in training have to be highly motivated and focused in their aims, taking their training into daily life and, independently, developing their skills further. Some are clearly aware of this: one of the Atlanta programme participants commented:

"I feel like I've gone from Kindergarten to third grade during the past 8 weeks of class. I'm still in elementary school, but I'm picking things up" (Kvasny \& Keil, 2006, p. 48).

This participant understood that he or she needed to continue to learn, in order to derive benefit from the new skills. Motivation is key to this and the evidence of research on some categories of disadvantaged persons is that, perhaps, more effort needs to be expended on motivating than on simply teaching new skills.

\section{ELDERLY PERSONS}

The significance of motivation is quite evident in the study of training for elderly people. Cody, Dunn, Hoppin, and Wendt (1999), note that almost half of the people (48\%), recruited to participate in a project of learning to use WebTV, withdrew in the first six weeks:

"Forty-five individuals (15\% of the entire sample) believed that WebTV was too difficult to learn, while 77 individuals (26\% of the entire sample) withdrew because they felt that they did not have sufficient time to devote to learning to use WebTV" (Cody et al., 1999, p. 261).

However, once trained, the remaining participants experienced feelings of social support and enjoyed being online. The organizers noted that similar interventions should concentrate on reducing anxiety and building efficacy even before the start of a programme. On the other hand, dependence upon proprietary systems is inadvisable (WebTV was closed down by Microsoft in 2013), since the skills gained need to be employed across generic types of technology.

A UK study confirmed that once the initial apprehension about the complexity of the technology is removed, confidence and interest of elderly people increased and skills developed (Hill, Betts, \& Gardner, 2015, p. 417). Hill et al. (2015) used two focus groups of older people (between the ages of 54 and 85 ) who had previously attended classes on digital inclusion. They were engaged in discussing their perceptions of digital technology and its effects on their lives. The results of the analysis of the focus group discussions showed that the participants appreciated the benefits that the technology could bring to them:

“Through enabling hobbies, social contact, and everyday tasks, DT [digital technology] facilitated more enjoyment, support, and flexibility into the lives of participants. This in turn supports social inclusion by enabling social connectedness, computer mediated social networks, and also opens up opportunities to introduce more enabling uses of DT...” (Hill et al., 2015, p. 419). 
On the other hand, participants in the focus groups, perceived some negative effects, seeing the 'always connected' nature of young people's lives as detrimental to their self-reliance and independence.

This last study did not actually evaluate a specifically designed training programme, however, it did produce evidence of the benefits of the technology, from those who overcame their initial barriers to Internet use.

Although we have found a number of publications that present information on the design and description of training or other digital interventions, they rarely incorporate an appropriate assessment of their impact on the participants. This was also noted by Green and Rossall (2015), whose research review registered five interventions for senior citizens in the UK between 2002-2013, which had rather weak impact evaluation mainly in terms of increased skills and confidence, social capital, wellbeing, and employability.

\section{INTER VENTION METHODS}

The interventions that we have found were carried out on different scales and with different audiences, ranging from deprived areas in large cities to village communities or smaller groups of representatives of the disadvantaged sections of the community. Some seemed to grow from a localized test of an idea into wide-spread experimentation in different countries (Mitra \& Dangwal, 2010), others were particularly designed for a clearly defined intervention to achieve a particular outcome (Wolf et al., 2017). Particular test instruments were used to measure the impact of an intervention, such as standard educational tests for particular secondary school subject, literacy, and mathematic skills (e.g., PISA instruments) (Vigdor et al., 2014) or testing reading pre-requisites (Wolf et al., 2017).

The success of the deployment of information technology in large cities was measured in terms of turn-up of local inhabitants at public access points, usage time, and, to some extent, interviews with the users. The impact of some large interventions can also be measured separately from the actual intervention, as was done in assessing the PCI in Argentina by interviewing youths from two different schools with different social profiles (Larghi et al., 2015) or conducting focus groups with elderly in the UK after the digital inclusion courses (Hill et al., 2015).

The usual instruments used in general exploration of digital inequalities are mainly statistical data on availability of the digital technology, deployment of the broadband connections, and penetration of digital technology into households or workplaces. In addition, questionnaire surveys (usually, selfcompleted) were used, sometimes representative of the whole population (e.g., Dutch case by van Deursen, Helsper, Eynon, \& van Dijk, 2017) or of a particular social group (e.g., Hatlevik et al., 2015). Qualitative methods are also applied for this exploration, such as semi-structured interviews (Tsai et al., 2015) or focus groups (Alam \& Imran, 2015). Which methods are applied depends on the research questions and approaches chosen by researchers, but many of the instruments, especially, validated questionnaires, may be adopted for research in other settings.

\section{DISCUSSION AND CONCLUSIONS}

\section{GROUPS AND AREAS ADDRESSED IN RESEARCH}

Looking into the overall digital divide research, especially in the area of physical and economic access to digital technology, one can say that the gap between some relational groups of inequality is closing, though at different rates in different countries. This can be said of the male/female, young/old relational groups, and to some extent low/high income groups as each new generation of technology lowers the price of equipment and connection. These relational inequality groups remain the same within countries, and the digital divide between them may depend on the country's own situation on the international scale of inequality. However, the gap between some groups remains the same, e.g. urban/rural or high/low education group. Moreover, new digital divides have been identified inside groups (e.g. high and low income and education influence on elderly persons or migrants' access to 
digital technology) confirming van Dijk's (2012) statement about the complexity of digital inequalities. It seems also that the gap in the quality of access (broadband connection, new and older equipment) remains, as it is closely connected with income inequality. Relational inequalities seem to be replicated in different settings: educational and children's literacy, employment and working life, access to cultural products and services, solving of everyday problems.

If physical access to digital technologies tends towards being reduced, the gap in digital and information skills and the usage benefits persists in most countries and populations, be it widely-studied older adults, young people, or migrants. It is also replicated within the usage patterns of different equipment, such as laptops, tablet computers, or smartphones.

\section{AIMS, METHODS, AND RESULTS OF INTER VENTIONS}

On the other hand, the literature shows that intentional interventions can result in positive outcomes of reducing relational inequalities, though this is not a question of simple deployment of public access points to the population or even distribution of advanced equipment among students or other social groups.

The area of education has attracted the largest number of interventions that were evaluated using valid tools. The success of these interventions (when it is registered) benefits mostly the most disadvantaged groups of students, but it depends more on successful pedagogical approaches than on the deployment of equipment as such. Though at first glance "the hole in the wall" (Mitra et al., 2005; Mitra \& Dangwal, 2010) or the project for the development of pre-requisites for literacy (Wolf, Ullman-Shade, \& Gottwald, 2012; Wolf et al., 2017) rely on "leaving the equipment for free access," closer examination reveals creative selection of learning approaches, teaching materials, and definition of aims and tasks for the participants in the experiment. The most important factors in these approaches are the reliance on collaborative learning and supporting creativity of the learners. It is not quite clear, but very probable, that negative impact from the deployment of computers and digital technology happens when these carefully developed strategies are absent.

Large interventions at a community level are rare and poorly equipped with valid evaluation data. However, they provide one more interesting finding about motivation of the targeted population. Provision of free public access points to the Internet and training possibilities may or may not attract citizens, depending on the situation of the community, and the dynamics and prospects of its development (Loader \& Keeble, 2004; Kvasny \& Keil, 2006). It is difficult to collect reliable data from such interventions and, especially, to assess the reasons for their success or failure.

The most popular type of intervention with migrant or elderly people is the evaluation of training programmes together with provision of access to some equipment. The outcomes of training in WebTV (Cody et al., 1999) and the classes of digital inclusion (Hill et al., 2015) with senior citizens show that the use of digital technology helps to reduce their social isolation and to increase a sense of well-being. However, they also need to consider the ease of use of the provided equipment, as well as the help needed to overcome initial anxiety and offer a sense of usefulness to the activity.

Thus, we can conclude that, in planning a digital intervention with the aim of reducing digital inequalities, one needs to assess carefully the context and the needs of participants. Similarly, methods must be devised to attract and retain their interest through collaborative interactions, and gradual increase in the complexity of tasks. The creative efforts of participants must be supported through the use of appropriate equipment and using properly devised learning materials based on sound pedagogical principles.

We will test these conclusions by applying an intervention in the context of Lithuanian towns of different sizes. The intervention will build on a common design of collaborative learning and similar type of materials but employ different pedagogical approaches and support to three groups of participants from different disadvantaged social groups. We expect to prepare policy recommendations for 
educational and cultural institutions in Lithuania after the conclusion of this intervention. However, this literature review allows us to suggest that Lithuanian educational institutions could invest in the design of well-grounded pedagogical and didactic strategies for collaborative digital literacy programmes among the most disadvantaged students as this group demonstrates the most significant advances in conquering the digital gap that exists with more affluent students.

\section{REFERENCES}

Akamai. (2017). Akamai's state of the Internet: Q1 2017 report. Retrieved from https://www.akamai.com/uk/en/multimedia/documents/state-of-the-Internet/q1-2017-state-of-theInternet-connectivity-report.pdf

Alam, K., \& Imran, S. (2015). The digital divide and social inclusion among refugee migrants: A case in regional Australia. Information Technology and People, 28(2), 344-365. https://doi.org/10.1108/ITP-04-2014-0083

Björklund, A., \& Freeman, R. B. (1994). Generating equality and eliminating poverty, the Swedish way (Working Paper No. 4945). Cambridge, MA: National Bureau of Economic Research. https://doi.org/10.3386/w4945

Blank, G. (2014, June 21). Mapping the local geographies of digital inequality in Britain [Web log entry]. The Policy and Internet Blog. Retrieved from http://blogs.oii.ox.ac.uk/policy/mapping-the-local-geographies-ofdigital-inequality-in-britain/

Carlson, E., \& Goss, J. (2016). The state of the urban/rural digital divide. Washington, DC: National Telecommunications and Information Administration. Retrieved from https://www.ntia.doc.gov/blog/2016/stateurbanrural-digital-divide

Chen, W., \& Wellman, B. (2004). The global digital divide - Within and between countries. IT \& Society, 1(7), $18-25$.

Cody, M. J., Dunn, D., Hoppin, S., \& Wendt, P. (1999). Silver surfers: Training and evaluating Internet use among older adult learners. Communication Education, 48(4), 269-286. https://doi.org/10.1080/03634529909379178

Colombo, F., Aroldi, P., \& Carlo, S. (2015). Nuevos mayores, viejas brechas: TIC, desigualdad y bienestar en la tercera edad en Italia [New elders, old divides: ICTs, inequalities and well-being amongst young elderly Italians.] Comunicar, 23(45), 47-55. https://doi.org/10.3916/C45-2015-05

Elliott, L. (2016, October 2). World Bank renews drive against inequality. The Guardian. Retrieved from https://www.theguardian.com/business/2016/oct/02/world-bank-renews-drive-against-inequality-imf

Fairlie, R. W. (2017). Have we finally bridged the digital divide? Smart phone and Internet use patterns by race and ethnicity. First Monday, 22(9). https://doi.org/10.5210/fm.v22i9.7919

Federal Communications Commission. (2016). 2016 measuring broadband America. Fixed broadband report. A report on consumer fixed broadband performance in the United States. Washington, DC: Author. Retrieved from https://www.fcc.gov/reports-research/reports/measuring-broadband-america/measuringfixed-broadband-report-2016

Green, M., \& Rossall, P. (2013). Digital inclusion evidence review. Retrieved from https://www.ageuk.org.uk/globalassets/age-uk/documents/reports-and-publications/reports-andbriefings/active-communities/rb sept13 age uk digital inclusion evidence review.pdf

Hargittai, E., \& Dobransky, K. (2017). Old dogs, new clicks: Digital inequality in skills and uses among older adults. Canadian Journal of Communication, 42(2). https://doi.org/10.22230/cjc.2017v42n2a3176

Hargittai, E. (2002). Second-level digital divide: Differences in people's online skills. First Monday, 7(4). https://doi.org/10.5210/fm.v7i4.942

Hatlevik, O. E., Björk Guðmundsdóttir, G., \& Loi, M. (2015). Digital diversity among upper secondary students: A multilevel analysis of the relationship between cultural capital, self-efficacy, strategic use of information and digital competence. Computers \& Education, 81(C), 345-353. https://doi.org/10.1016/i.compedu.2014.10.019 
Hill, R., Betts, L., \& Gardner, S. (2015). Older adults' experiences and perceptions of digital technology: (Dis)empowerment, wellbeing and inclusion. Computers in Human Behavior, 48, 415-423. https://doi.org/10.1016/j.chb.2015.01.062

Internet World Stats. (2017a). Internet stats and Facebook usage in Europe March 2017 statistics. Retrieved from http://www.Internetworldstats.com/stats4.htm\#europe

Internet World Stats. (2017b). World Internet usage and population statistics, March 31, 2017 - update. Retrieved from http://www.Internetworldstats.com/stats.htm

Kabbar, E. F., \& Crump, B. J. (2006). The factors that influence adoption of ICTs by recent refugee immigrants to New Zealand. Informing Science: the International Journal of an Emerging Transdiscipline, 9, 111-121. https://doi.org/10.28945/475

Koike, Y. (2015). Why inequality is different in Japan. World Economic Forum. Retrieved from https://www.weforum.org/agenda/2015/03/why-inequality-is-different-in-japan/

Kvasny, L., \& Keil, M. (2006). The challenges of redressing the digital divide: A tale of two U.S. cities. Information Systems Journal, 16(1), 23-53. https://doi.org/10.1111/j.1365-2575.2006.00207.x

Kwong, Y. H. (2015). Digital divide: Computer and Internet use by elderly people in Hong Kong. Asian Journal of Gerontology and Geriatrics, 10(1), 5-9.

Larghi, B. S., Lemus, M., Moguillansky, M., \& Welschinger, L. N. (2015). Digital and social inequalities: A qualitative assessment of the impact of the connecting equality program on Argentinean youth. Electronic Journal of Information Systems in Developing Countries, 69(1), 1-20. https://doi.org/10.1002/j.16814835.2015.tb00496.x

Liubiniené, V., \& Thunqvist, D. P. (2015). Media literacy and digital divide: A cross-cultural case study of Sweden and Lithuania. Creativity Studies, 8(2), 134-148. https://doi.org/10.3846/23450479.2015.1046407

Lloyd, A., Kennan, M. A., Thompson, K.M., \& Qayyum, K. (2013). Connecting with new information landscapes: Information literacy practices of refugees. Journal of Documentation, 69(1), 121-144. https://doi.org/10.1108/00220411311295351

Lloyd, A., Pilerot, O., \& Hultgren, F. (2017). The remaking of fractured landscapes: Supporting refugees in transition (SpiRiT). Information Research, 22(3). Retrieved from http://www.informationr.net/ir/223/paper764.html

Loader, B. D., \& Keeble, L. (2004). Challenging the digital divide? A literature review of community informatics initiatives. York, U.K.: Joseph Rowntree Foundation. Retrieved from https://www.jrf.org.uk/ file/37023/download?token=kI1HIK5A\&filetype=full-report

Mitra, S., \& Dangwal, R. (2010). Limits to self-organising systems of learning - The Kalikuppam experiment. British Journal of Educational Technology, 41(5), 672-688. https://doi.org/10.1111/j.1467-8535.2010.01077.x

Mitra, S., Dangwal, R., Chatterjee, S., Jha, S., Bisht, R. S., \& Kapur, P. (2005). Acquisition of computing literacy on shared public computers: Children and the "hole in the wall." Australasian Journal of Educational Technology, 21(3), 407-426. https://doi.org/10.14742/ajet.1328

Nord, J. H., Lee, T. R., Cetin, F., Atay, Ö., \& Paliszkewicz, J. (2016). Examining the impact of social technologies on empowerment and economic development. International Journal of Information Management, 36(6), Part A, 1101-1110. https://doi.org/10.1016/j.ijinfomgt.2016.08.001

Nord, J. H., Paliszkiewicz, J., Grublješič, T., Scarlat, C., \& Svanadze, S. (2015). Women’s empowerment: Social technologies in Slovenia, Romania, and Georgia. Online Journal of Applied Knowledge Management, 3(1), 128150. Retrieved from http://www.iiakm.org/ojakm/articles/2015/volume3 1/OJAKM Volume3 1pp128150.pdf

OECD. (2016). Income inequality remains high in the face of weak recovery. Retrieved from http://www.oecd.org/social/OECD2016-Income-Inequality-Update.pdf

Ofcom. (2017). UK home broadband performance. The performance of fixed-line broadband delivered to UK residential customers. Retrieved from https://www.ofcom.org.uk/ data/assets/pdf file/0015/100761/UK-homebroadband-performance,-November-2016-Technical-report.pdf 
Ono, H., \& Zavodny, M. (2008). Immigrants, English ability and the digital divide. Social Forces, 86(4), 14551479. https://doi.org/10.1353/sof.0.0052

Ookla. (2016). Speedtest $₫$ market report: United States. Retrieved from http://www.speedtest.net/reports/unitedstates/2016/

Oxfam. (2017). An economy for the 99\%: Briefing paper. Retrieved from https://www.oxfam.org/sites/www.oxfam.org/files/file attachments/bp-economy-for-99-percent160117-en.pdf

Quan-Haase, A., Martin, K., \& Shreurs, K. (2016). Interviews with digital seniors: ICT use in the context of everyday life. Information, Communication \& Society, 19(5), 691-707. https://doi.org/10.1080/1369118X.2016.1140217

Pick, J., \& Sarkar, A. (2016). Theories of the digital divide: Critical comparison. Proceedings of the 2016 49th Hawaii International Conference on System Sciences (HICSS) (pp. 3888-3897). Washington, DC: IEEE Computer Society. https://doi.org/10.1109/HICSS.2016.484

RaskInterneta. (2017). Plačiajuosčio ryšio žemèlapis [Broadband map]. Retrieved from http://www.raskInterneta.lt/zemelapis

Rawls, J. (1999). A theory of justice (Rev. ed.). Cambridge, MA: Harvard University Press.

Salemink, K., Strijker, D., \& Bosworth, G. (2017). Rural development in the digital age: A systematic literature review on unequal ICT availability, adoption, and use in rural areas. Journal of Rural Studies, 54, 360-371. https://doi.org/10.1016/j.jrurstud.2015.09.001

Sassi, S. (2005). Cultural differentiation or social segregation? Four approaches to the digital divide. New Media \& Society, 7(5), 684-700. https://doi.org/10.1177/1461444805056012

Stewart, J., Bleumers, L., Van Looy, J., Mariln, I., All, A., Schurmans, D., Willaert, K., ... Misuraca, G. (2013). The potential of digital games for empowerment and social inclusion of groups at risk of social and economic exclusion: Evidence and opportunity for policy. Seville: Joint Research Centre, European Commission.

Tilly, C. (1998). Durable inequality. Berkeley: University of California Press.

Tsai, H. Y. S., Shillair, R., Cotton, S. R., Winstead, V., \& Yost, E. A. (2015). Getting Grandma online: Are tablets the answer for increasing digital inclusion for older adults in the US? Educational Gerontology, 41(10), 696709. https://doi.org/10.1080/03601277.2015.1048165

Tsetsi, E., \& Reins, S. A. (2017). Smartphone Internet access and use: Extending the digital divide and usage gap. Mobile Media \& Communication, 5(3), 239-255. https://doi.org/10.1177/2050157917708329

United Nations Development Programme. (2009). Human development report 2009. Overcoming barriers: buman mobility and development. Basingstoke, UK: Palgrave Macmillan. Retrieved from http://hdr.undp.org/sites/default/files/reports/269/hdr 2009 en complete.pdf

U.S. Census Bureau. (2014). Computer and Internet access in the United States: 2012. Washington, DC: Author. Retrieved from https://www.census.gov/data/tables/2012/demo/computer-Internet/computer-use2012.html

U.S. National Telecommunications and Information Administration. (1995). Falling through the net: a survey of the 'bave nots' in rural and urban America. Washington, DC: Department of Commerce. Retrieved from https://www.ntia.doc.gov/ntiahome/fallingthru.html

U.S. National Telecommunications and Information Administration. (1998). Falling through the net II: New data on the digital divide. Washington, DC: Department of Commerce. Retrieved from https://www.ntia.doc.gov/report/1998/falling-through-net-ii-new-data-digital-divide

U.S. National Telecommunications and Information Administration. (1999). Falling through the net: Defining the digital divide. Washington, DC: Department of Commerce. Retrieved from https://www.ntia.doc.gov/legacy/ntiahome/fttn99/contents.html

van Dijk, J. A. G. M. (2005). The deepening divide: Inequality in the information society. London: Sage Publication. 
van Dijk, J. A. G. M. (2012). The evolution of the digital divide: The digital divide turns to inequality of skills and usage. In J. Bus, M. Crompton, M. Hildebrandt, \& G. Metakides (Eds), Digital enlightenment yearbook, 2012 (pp. 57-75). Amsterdam: IOS Press.

van Duersen, A. J. A. M., \& Helsper, E. J. (2015). The third level digital divide: Who benefits most from being online? Communication and Information Technologies Annual, 10, 29-53. Retrieved from http://doc.utwente.nl/97634/1/CH002.pdf

van Deursen, A. J. A. M., Helsper, E .J., Eynon, R., \& van Dijk, J. (2017). The compoundness and sequentiality of digital inequality. International Journal of Communication, 11, 453-473. Retrieved from http://eprints.lse.ac.uk/68921/1/Helsper Compoundness $\% 20 a n d \% 20$ sequentiality.pdf

van Deursen, A. J. A. M., \& van Dijk, J. (2010). Internet skills and the digital divide. New Media \& Society, 13(6), 893-911. https://doi.org/10.1177/1461444810386774

Venkatesh, V. (2000). Determinants of perceived ease of use: Integrating control, intrinsic motivation, and emotion into the technology acceptance model. Information Systems Research, 11(4), 342-365. https://doi.org/10.1287/isre.11.4.342.11872

Vigdor, J. L., Ladd, H. F., \& Martinez, E. (2014). Scaling the digital divide: Home computer technology and student achievement. Economic Inquiry, 52(3), 1103-1119. https://doi.org/10.1111/ecin.12089

Warschauer, M. (2002). Reconceptualizing the digital divide. First Monday, 7(7). https://doi.org/10.5210/fm.v7i7.967

Wilding, R. (2012). Mediating culture in transnational spaces: An example of young people from refugee backgrounds. Continuum, 26(3), 501-511. https://doi.org/10.1080/10304312.2012.665843

Wolf, M., Ullman-Shade, C., \& Gottwald, S. (2012). The emerging, evolving reading brain in a digital culture: Implications for new readers, children with reading difficulties, and children without schools. Journal of Cognitive Education and Psychology, 11(3), 230-240. https://doi.org/10.1891/1945-8959.11.3.230

Wolf, M., Gottwald, S., Breazeal, C., Galyean, T., \& Morris, R. (2017). “I Hold Your Foot:” Lessons from the reading brain for addressing the challenge of global literacy. In A. Battro, P. Léna, M. Sánchez Sorondo, \& J. von Braun (Eds), Children and sustainable development (pp. 225-238). Cham: Springer International Publishing. https://doi.org/10.1007/978-3-319-47130-3 17

Žilinskas, G. (2011). Lietuvos Respublikos darnaus vystymosi politika: Skaitmeninès atskirties problemos regioninis aspektas [Policy of sustainable development of the Republic of Lithuania: Regional aspect of digital divide]. Vadybos mokslas ir studijos - kaimo verslu ir ju infrastruktüros plètrai, 11(25), 262-270.

Žilinskas, G. (2012). Skaitmeninès atskirties Lietuvos Respublikos regionuose analizè [Analysis of digital divide in regions of the Republic of Lithuania]. Viešoji politika ir administravimas, 11(3), 502-513.

\section{ACKNOWLEDGMENT}

The article is written within the framework of the project, The stimulation of digital reading as a means of reduction the digital divide (2017-2018) financed by Research Council of Lithuania (Nr. GER-002/2017). 


\section{BIOGRAPHIES}

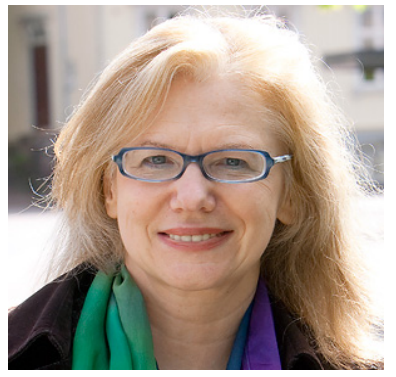

Elena Maceviciute is a Professor in the Swedish School of Librarianship and Information Science, University of Borås. She is also a Professor in the Faculty of Communication, Vilnius University, Lithuania and a member of the Digital Media Lab. Her research relates to information use in organizations, digital libraries and resources, and, currently, the role of e-books and digital reading in modern society. Elena has participated in large European research and educational projects and conducted research projects on a national scale in Sweden and Lithuania. She has published over 300 research, educational, and professional articles. Elena Maceviciute is a deputy editor of the Information Research: an international electronic journal and is a member of editorial boards of several other international and national research journals. She can be contacted at elena.maceviciute@gmail.com

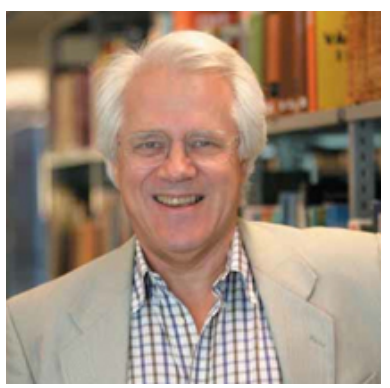

Thomas D. Wilson is Senior Professor, University of Borås, Sweden. He is also Visiting Professor at the University of Leeds Business School and Professor Emeritus of the University of Sheffield, U.K. He has received Honorary Doctorates from the Universities of Gothenburg, Sweden and Murcia, Spain. He has carried out research in a variety of fields from the organizational impact of information technologies and information management to human information behaviour and, most recently, on digital libraries and the situation of e-books in Sweden. He founded and continues to edit the open access journal Information Research. In 2017 he was the recipient of the Award of Merit of the Association for Information Science and Technology. He can be contacted at wilsontd@gmail.com. 